\title{
myFutureMails.com: A Site that Uses Email to Help in Revealing the Existence of Unclaimed Property to Potential Owners
}

\author{
Evans A. K. Miriti \\ School of Computing and Informatics \\ University of Nairobi, Kenya
}

\begin{abstract}
Unclaimed assets exist as a result of institutions that have custody of the assets losing contact with the owner of the assets or their beneficiaries. In some jurisdictions, such assets are turned over to state agencies that try to locate the owners. Some of these agencies have developed web portals that enable potential owners and beneficiaries to search the unclaimed assets databases. For asset owners that die intestate, their next of kin may have no way of knowing what assets their departed relative owned. In this paper, the details of a web portal that enables an asset owner to disclose their assets to their beneficiaries only after the owner's demise is described. The portal uses "Are you alive messages" to determine if the owner is still living.
\end{abstract}

\section{General Terms}

Web Portal, Unclaimed Assets, Unclaimed Property, Email, Website

\section{Keywords}

Web Portal, unclaimed Assets, unclaimed property, intestate, will, claims, life insurance, search, email, future email

\section{INTRODUCTION}

According [5], American states were reputed to be holding $\$ 41.7$ billion in unclaimed property. [4] Quoting a report from the Financial Times states that the estimated value of unclaimed assets in UK is approximately 77 billion pounds. In Kenya, the value of unclaimed assets held by the Unclaimed Financial Assets Authority were valued at approximately 5.5 billion KES [1].

Unclaimed assets can take the form of: unclaimed insurance policies; abandoned, dormant and forgotten bank accounts; stocks; dividends; and mutual funds; bonds which have not been redeemed; unclaimed lottery winnings; safe box deposits; unclaimed retirement benefits; lands and building among others.

There are various reasons why assets may become unclaimed. One of the top reasons is when the owner dies intestate (without a will). In such a situation, if the dead person had not disclosed some of his assets to their next of kin or heirs, then the heirs will have no way of knowing that these assets exist in order for them to claim them. Another cause of unclaimed assets is when the owner forgets of the existence of the assets [6]. According to [4], assets are considered unclaimed due to loss of contact with the owner which may be as a result of changing of names after marriage or divorce, unreported change of address, expired or invalid postal forwarding address and or illegible records. Other reasons for unclaimed assets are negligence, ignorance, relocation and poor record keeping [3].
Authorities in different jurisdictions have taken steps to try and solve the unclaimed assets problem. Usually, the main goal is to try and locate the owner or their next of kin. Another goal is for people who suspect that they may be beneficiary of unclaimed assets to be able to have a means of searching the unclaimed assets registries. Authorities also try to compel institutions such as banks to disclose and surrender unclaimed assets. Private companies have also come up with initiatives to help potential beneficiaries trace their unclaimed assets.

In Kenya, the Unclaimed Financial Assets Authority (UFAA) is responsible for identifying and managing unclaimed financial assets. It is also responsible for processing claims by potential beneficiaries. UFAA classifies assets as unclaimed "when they appear to have been forsaken by their owner by virtue of no generated activity and to which it is presumed the owner has relinquished his or her interest to the property without vesting such interest in another person or entity" [3]. UFAA manages the money it receives as unclaimed assets using a trust fund and make efforts to "reunite the funds with their owners". There is not limit to the amount of time the potential owner can take to file a claim. The authority provides an online portal(http://www.ufaa.go.ke/) which contains a form for potential beneficiaries or claimants to inquire about unclaimed property. The online portal also contains a search feature which can be used by interested parties to find out if a person they are interested in is listed as an owner of unclaimed assets. Holders of unclaimed assets such as banks are responsible for identifying and remitting unclaimed assets to the UFAA. Failure to do so can attract penalties such as interests on the held properties.

Other jurisdictions also try to provide automated ways for people to to claim unclaimed assets. For instance the online portal https://ucpi.sco.ca.gov/UCP/Default.aspx is provided by the California State Controller to assist interested parties in locating unclaimed properties that may be of interest to them. The portal also provides a search feature for people to be able to search the unclaimed assets database. The office also identifies and sends out notices to potential beneficiaries and owners of unclaimed propeties in an effort to reconnect the properties with their rightful owners [6]. The site allows allows for online submission for claims below $\$ 5000$.

\section{SYSTEM GOAL}

While the efforts aimed at securing, and locating the owners of unclaimed assets are laudable, it is incumbent upon each person to ensure that their assets do not end up in the unclaimed assets list or database. In fact, some assets in these databases may never find their way to the rightful owners probably due to the negligence of the owners or their ignorance concerning the procedures involved. In addition, 
some types of assets cannot find their way in the unclaimed assets databases particularly when the assets are not in the custody of institutions such as financial institutions and insurance companies. Examples of such assets are land and buildings.

The goal of the site https://myfuturemails.com is to enable anyone with properties to disclose to their potential beneficiaries of the assets that they will have left behind after their demise. The site assumes that the owner of the property may not be free to make the disclosure immediately and that they would rather make the disclosure at a future date. They may however never be able to make the disclosure for various reasons including death, serious sicknesses or injuries and mental incapacitation among others. One of the reasons that people may hesitate to disclose their assets to their next of kin is due to the possibility of being harmed by the potential beneficiaries who may want the owner out of the way so that they can claim the asset(s). As an example, in April 2017 The Telegraph reported of a case in which a wife plotted her husband's murder in order to cash in on the life insurance [2].

\section{SYSTEM REQUIREMENTS}

To be able to meet it stated goal, the system needs to provide the following features: i. Enable users to create future emails in which they list their assets and any other information that the potential beneficiaries may need to know about the asset(s)

ii. Enable the users to provide a list of recipient emails for the future email

iii. Enable the user to attach any necessary documents that the potential beneficiaries may use to prove ownership or identity of the asset(s). These documents may include photos, videos, audio recordings and even scanned copies of the owner's will.

iv. Enable the user to stop the future email from being sent for as long as they are able (not deceased or suffered from an illness or injury that renders them unable to manage the property).

v. Provide adequate security considering that the information that is to be stored is sensitive in nature.

\section{SYSTEM OPERATION}

In order to use the system, the assets owner should visit the site https://myfuturemails.com and follow the following steps:

\subsection{Register}

This involves providing ones details including names, email, phone number and country. There is also an email verification step that involves responding to an email sent from the site.

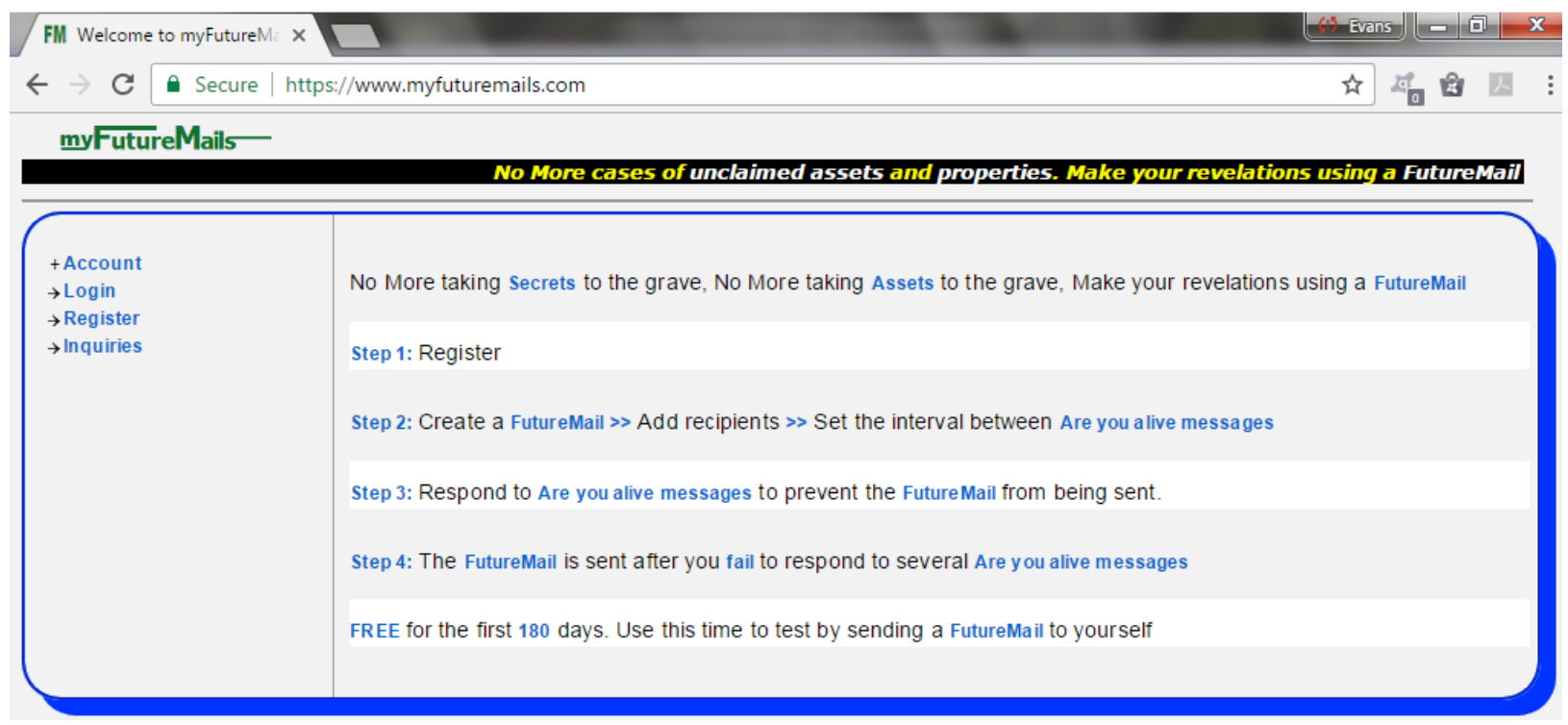

Fig 1: myfuturemails.com home page

\subsection{Create a Future Mail}

One can create as many future emails as they want. There are however space limitations to prevent misuse since it is expected that video, audio and image files that may need a lot of space will be uploaded. Some initial space is provided for free but one may purchase additional space.

To create a future mail, one provides the following fields: To, $\mathrm{CC}$ and BCC just as in an ordinary email; the subject, the body and attachments. Information related to the frequency and number of "Are You Alive Messages" is also provided. Any media files such as photos are expected to be provided as attachments. Once the FutureMail has been created, it is saved rather than sent. When saved, the FutureMail goes to an outbox from where the owner can access it and make changes.

\subsection{Respond to "Are You Alive Messages"}

"Are You Alive Messages" are the main mode of controlling the sending or not sending of the FutureMail to the set recipients. The owner decides the frequency (days between "Are You Alive Messages") and how many consecutive un-responded to "Are You Alive Messages" will cause the FutureMail to be sent. If the owner fails to respond to several consecutive to "Are You Alive Messages" (as set by the owner), the system assumes that the owner is dead or incapacitated and sends the FutureMail to the potential beneficiaries indicated in the FutureMail's To, CC and BCC list. The "Are You Alive Messages" are sent in the form of emails. The "Are You Alive Messages" email has a link on which the owner clicks. The act of clicking the link acts as the response to the "Are You Alive Messages" and the response is displayed on a browser. 
In addition to the usage steps describe above, the system requires that the user pays a small annual subscription fee after 180 days of free usage. This is necessary in order to support the cost of maintaining the site. One can make subscriptions ranging from one year to ten years. Every subscription results in additional space being allocated to the owner. The owner can also change their password and also perform other account maintenance operations.

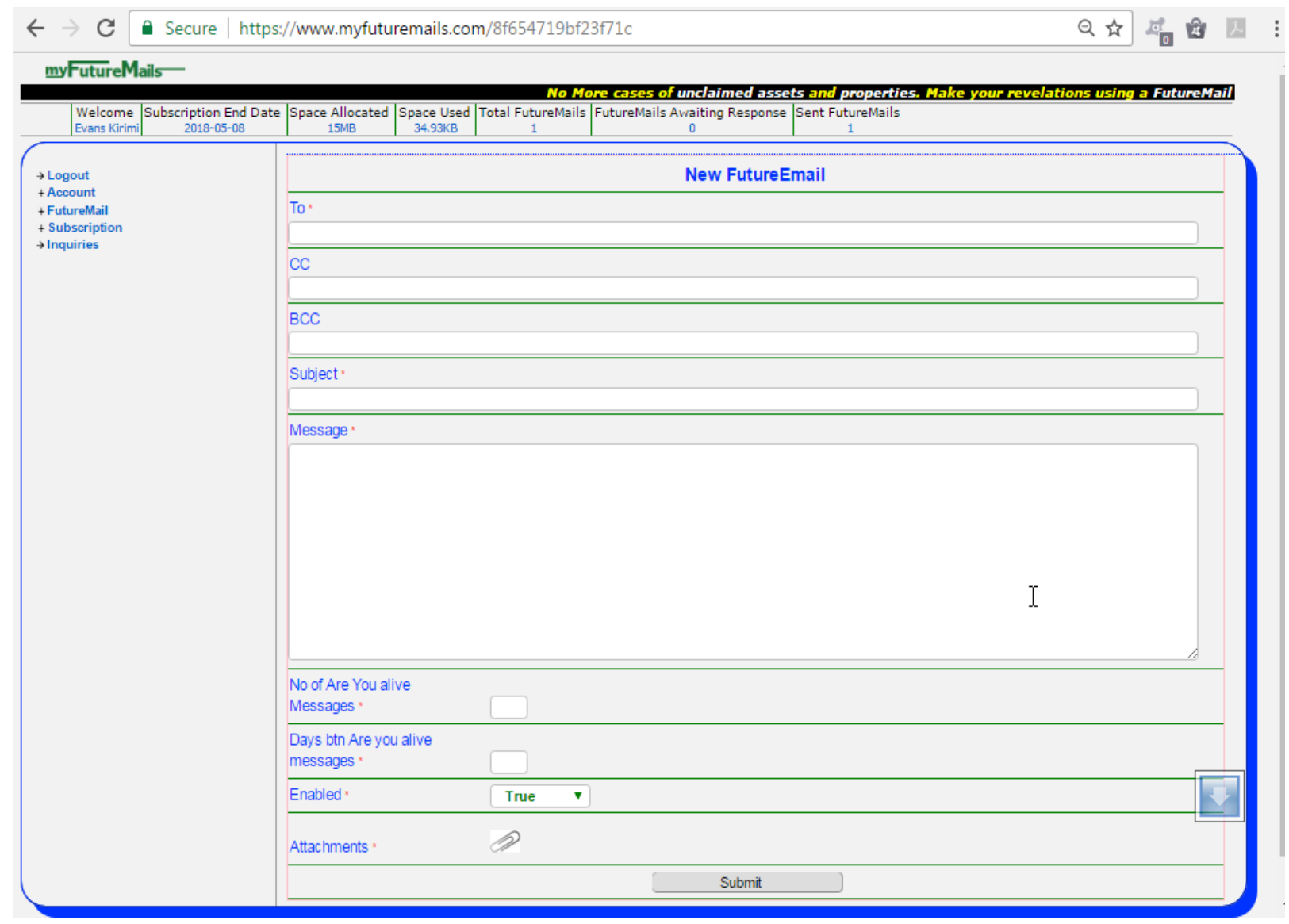

Fig 2: A FutureMail creation page

\section{FUTURE WORK}

As it is, the system right now is optimized for desktop/laptop displays. Tablet users may also get a reasonable view. However the site needs to be optimized to be device responsive so that smart phone users and other users of mobile devices may get a more optimized view.

\section{CONCLUSION}

http://myfuturemails.com is meant to be one of the tools available to asset owner's to prevent their assets from becoming unclaimed. Even though owners have the option of writing wills, this may not be enough since wills can be forged. To prevent this, the will can be scanned and attached to the FutureMail and all beneficiaries or their representative can receive a copy of the genuine will when they receive the FutureMail.

An additional potential use of the site is to report crime which one knows about but they are afraid to disclose about when they are alive. One can also disclose potential threats to their lives so that in case something happens to them, a FutureMail can be sent to the authorities who will then know where to begin their investigations.

\section{REFERENCES}

[1] Auditor-General. "The Financial Statements of Unclaimed Assets Trust Fund for the Year ended 30th June 2016.” Nairobi, 2016.

[2] The Telegraph. Wife plotted husband's murder to cash in life insurance, court hears. 09 April 2017. http://www.telegraph.co.uk/news/uknews/crime/1031825 0/Wife-plotted-husbands-murder-to-cash-in-lifeinsurance-court-hears.html (accessed April 10, 2017).

[3] UFAA. FAQs. 2016. http://www.ufaa.go.ke/ index.php/faq (accessed April 2017).

[4] Unclaimed Assets UK. Trace and Claim Missing Assets in the UK. http://unclaimedassets.co.uk/ (accessed April 2017).

[5] Williams, Geoff. How To Find Unclaimed Money And Property. 2013. https://www.forbes.com/sites/ nextavenue/2013/06/27/how-to-find-unclaimed-moneyand-property/\#3ea548dc1864 (accessed March 2017).

[6] Yee, Betty T. Unclaimed Property Main Page. http://sco.ca.gov/upd.html (accessed April 2017). 